Note: This is a pre-copy-editing, author-produced PDF of an article accepted for publication in Drugs:

Education, Prevention and Policy following peer review. The definitive publisher-authenticated version [Tilki M (2006) The social contexts of drinking among Irish men in London: Evidence from a qualitative study, Drugs: Education, Prevention and Policy, 13(3). 247-261] is available online at

http://www.informaworld.com/smpp/title content=t713412630

\title{
The social contexts of drinking among Irish men in London :
}

\author{
Evidence from a qualitative study
}

\section{Dr Mary Tilki}

Mary Tilki,

Principal Lecturer,

School of Health and Social Sciences,

Middlesex University,

Queensway,

Enfield

EN3 4SA

$0208-411-5150$

m.tilki@mdx.ac.uk 


\title{
The social contexts of drinking among Irish men in London : evidence from a qualitative study
}

\section{Mary Tilki}

Published in Drugs: Education, Prevention and Policy, 2006, 13(3), 247 -261

Copyright: Taylor \& Francis

\begin{abstract}
The article reports aspects of a qualitative study which examined health beliefs and behaviours among Irish people in London. The findings elicited though focus groups and semi structured interviews, demonstrate excessive alcohol among men who left Ireland in the 1950s and 1960s, which was related to socio-economic, housing and migration factors. The pub filled economic and social functions for men working mainly in construction and who felt homesick and isolated in an unwelcoming and often hostile environment. Irish masculinity was constructed around a combination of hard physical labour and heavy drinking and alcohol became a culturally sanctioned coping strategy for men economically inactive because of injury, degenerative disorders or redundancy or with underlying mental illness. The findings demonstrate discrimination and insensitivity in primary care, mental health and social services dealing with alcohol problems. The study uncovered a tolerance of heavy alcohol use and alcoholism in the Irish community in London which may reflect a continuation of social and cultural attitudes in Ireland. This requires further investigation but the findings illuminate the function and meaning of alcohol for Irish men in London, highlight the need for action by UK policy makers and potentially inform health and social care practice.
\end{abstract}




\section{The social contexts of drinking among Irish men in London : evidence from a qualitative study}

This paper addresses the evidence of Irish misuse of alcohol in the UK and specifically focuses upon an analysis of qualitative data on the experiences of middle aged and older Irish men. It explores the social contexts of problematic drinking among Irish men and the extent to which past patterns have continuing resonance for the Irish abroad. It argues that addressing problem drinking among sections of the Irish community in Britain requires that the context and the experience of being Irish in Britain be understood by policymakers and practitioners so that health promotion and therapeutic interventions are effective in addressing this issue of concern.

\section{The background: stereotypes, patterns and neglect}

The stereotype of the Irish drunk is well known in popular and professional circles and has created a sensitivity around alcohol misuse by Irish people. As with most stereotypes, it is comprised of a popular myth with a level of truth which helps to sustain it and account for its persistence in Britain and elsewhere. While adherence to this stereotype has a detrimental impact on Irish people, it is important to recognise that there are real problems associated with the misuse of alcohol among sections of the Irish community in the UK.

The 1999 Health Survey for England included Irish first and second generation people in Britain for the first time and demonstrated that they were more likely to drink alcohol and to drink more frequently than the general population or other minority ethnic groups (Erens et al 2001). Irish men and women were less likely to be non-drinkers and both were much more likely to consume alcohol in excess of the government recommendations. Greater amounts of alcohol were responsible for the higher mean consumption levels for both Irish women and men. Although National Statistics Online website generally renders the Irish invisible by incorporating them into the "White" category, it 
unusually presents a specific table based on the Health Survey for England identified by a caption entitled "Alcohol consumption : Irish most likely to exceed advised levels" (http://www.statistics.gov.uk/cci/nugget.asp?id=264). In a preliminary study, Mc Cambridge et al (2004) compared patterns of alcohol consumption among Irish pub drinkers in London and Dublin. They found significantly higher alcohol consumption levels in London than in Dublin. Based on the recommended weekly thresholds, drinkers in London were much more likely than the Dubliners to be categorised in the high consumption and much less likely to fit into the low consumption type. There was evidence of raised alcohol dependency scores in both cohorts with male gender and younger age at higher risk.

The relationship between alcohol, mortality and morbidity among Irish migrants was first reported almost 30 years ago (Cochrane, 1977) and at intervals since (Dean at al 1981, Cochrane and Bal 1989). There is substantial evidence that alcohol related mortality in England and Wales among Irish born people is higher than in the general population or minority ethnic groups (Harrison et al 1997). Alcohol problems are closely related to homelessness, marginalisation, poverty, social isolation and occupational history (Harrison and Carr-Hill 1992, Harrison et al 1993, Harrison et al 1997, Commander et al 1999a,b) Alcohol contributes in a significant way to physical and mental ill-health and accounts for elevated admissions to both general and psychiatric hospitals (Canning et al 1999, Commander, 1999a,b). In a study of hospital admissions, Walls (1997) identified that Irish people admitted with psychiatric disorders were also likely to have a secondary diagnosis of alcohol misuse. There is a high incidence of suicide among the Irish community in Britain (Bracken et al 1998, Leavey, 1999) and although no link has been made for Irish people in England, there is a body of evidence linking suicide with alcohol and substance misuse in Northern Ireland (Foster, 2001) and in the Republic of Ireland (Farren and Martin 2004). 
There is some evidence that Irish people with alcohol problems are more likely to be treated in psychiatric hospitals (Cochrane and Bal 1989, Commander et al 1999a). Conversely a high proportion of clients seeking help from alcohol treatment agencies in the UK are known to be Irish (Luce et al 1999). Irish voluntary sector organisations in England report that a significant proportion of their work relates to providing advice and support to people with a range of problems associated with the use of alcohol (Kowarzik, 2001, 2002). In addition a number of Irish organisations in England provide culturally sensitive services to people with mental health problems, many of which are compounded by or in some way related to alcohol misuse. This in part reflects a lack of mental health skill among GPs and other professionals in dealing with Irish people presenting with alcohol problems (Tilki, 2003). A recent Department of Health Report (NIMHE, 2003) highlights the offence caused by the alcohol stereotype and points to the risk of misdiagnosing mental illness when Irish culture is equated with alcohol problems. It is not clear whether Irish people suffer general service problems around "dual diagnosis" or whether they are disproportionately labelled as having drink problems because of their cultural identity. It is also possible that acknowledging an alcohol problem is less stigmatising for Irish people than admitting mental illness. Nonetheless, the relationship between alcohol and mental ill-health is complex and must be understood if Irish people are be helped to deal with either or both problems effectively and sensitively.

\section{Failure to address Irish misuse of alcohol}

Despite this evidence and the persistence of the drunken stereotype there has been scant attention by professionals and policy makers to addressing the problem and there has been little research in the area (Foster, 2003). Foster (2003) suggests that middle aged Irish alcohol misusers are discriminated against and Mc Cambridge et al (2004) argue that alcohol related needs of young people are 
overlooked. Some of this relates to the way in which ethnicity data are collected and used and in particular the way in which the Irish are aggregated in the White majority category making them invisible. Neglect may also be an acknowledgement of the inappropriateness and insensitivity of the drunken stereotype but without a clear strategy to deal with the real problem that exists in parts of the Irish community. The greater emphasis on tackling drug misuse for all groups also serves to disadvantage the Irish whose problems mainly relate to alcohol (Foster, 2003).

Notwithstanding the lack of attention to the problem in policy and practice, there is a growing body of evidence highlighting the need for urgent action. Despite statistical evidence of increased mortality as well as mental and physical morbidity from alcohol related disorders among Irish people in Britain, there has been limited attention to the issue. In particular there has been a neglect of the social and cultural aspects of the problem. Sociological variants are at least as important as physiological and psychological when trying to understand the relationship between alcohol and human behaviour (Heath, 2002). If this deficit is to be tackled, the role and functions of alcohol for Irish people must be understood and must underpin health promotion initiatives and strategies for reducing consumption.

\section{The analysis}

This article discusses the social context of problematic alcohol consumption among Irish men in the UK, exploring changes that have taken place and the continuities which have persisted over time. It describes the alcohol related findings from a wider qualitative study into the health of Irish people in London which explored social, cultural and economic factors, health beliefs and behaviours (Tilki, 2003). It is illustrated with narrative data collected through key informant and lay focus groups and semi-structured interviews in the year 2000. It focuses on the narratives of 
men aged fifty and over who had worked in the construction industry and who now experience social disadvantage, poor physical ill-health, excesses of mental illness and in particular depression and suicide. The stories recount a complex relationship between socio-economic and psychosocial factors and alcohol and as such several of the men were in contact with Irish voluntary sector agencies. Data from lay focus group members and key informant professionals describe the experience of being Irish in London and the difficulties with which men present to Irish agencies respectively.

\section{The centrality of the pub}

The social role of the pub for Irish men is documented both in popular literature (MacAmhlaigh, 1964, 1985, Keane, 1993, Macken, 1949) and in scholarly work (Greenslade,1997, 1995). Men who emigrated to the UK in the 1950s and 1960s, migrated as single people and worked predominantly in the informal economy of the construction industry known as "the lump". They were employed by building contractors on a casual basis, paid cash in hand and moved all over the UK, wherever their labour was needed. The "Irish" pub was central to this shadow economy as the place where contractors recruited men, where they were picked up, dropped off and paid their wages after a day of casual labour (Cowley, 2001, MacAmhlaigh,1964). However it was not socially acceptable to return home at the end of a days work and as there was an expectation that the work gang repair to the pub for the rest of the evening. Men who withstood this peer pressure were deemed poor mixers and risked not being offered further work (MacAmhlaigh, 1985). The concept of the pub as a "third place", a space between work and home (Oldenburg, 1999) is apt for past and present migrants. For Irish men in Britain the pub operated as a 'home from home' as well as an extension of the workplace. 
Seamus, now in his sixties describes the experience of living in London in the early 60s.

"When I came here first, I found that the majority of people my age when they came to this country there was no other place to go, only the pub. It was the only place to meet your mates. I was a Pioneer( abstainer) when I came to this country but I was living in an oul room, coming from work and getting the tea and going to going out again. Looking at the four walls. The entertainment was basically the pub, there was no other place to go.

Although the pub had an important economic function for Irish men in Britain, its wider social functions cannot be underestimated. It afforded an escape from overcrowded and inhospitable digs, shared with strangers and where visitors were not allowed. "Irish" pubs were a refuge from wider social isolation and alienation, offering a safe cultural environment to meet old friends, get news from home and enjoy camaraderie, craic (fun) and music. While Oldenburg's (1999) idea of the "third space" is broadly applicable for many groups, the "Irish pub" had and arguably still has an additional and important dimension. Irish people have faced racism, discrimination and harassment over the decades but particularly in the wake of the Prevention of Terrorism Act in 1974 (Hickman and Walter 1997). This act gave draconian powers to the police but also appeared to legitimate anti-Irish sentiment, suspicion and harassment by members of the public (Hillyard, 1993). The "Irish" pub offered an escape from hostility and afforded a safe space to be Irish and to interact with other Irish people and cope with isolation.

Shane a social worker working within the Irish community in London explains 
"Many Irish people emigrated alone and there isn't the extended family here in the same way as there is for other ethnic groups and it[pub]does help, otherwise you're sitting indoors on your own”.

According to Heath (2000) the public drinking place has a key function in facilitating sociability and alcohol promotes relaxation and conviviality. In most cultures, rules around drinking stipulate that alcohol is consumed in a sharing social context with goodwill and bonhomie. The public space of the pub enabled Irish men from different counties, working with different contractors or at distant parts of large construction sites to socialise with friends and get to know others. It was particularly important for significant numbers of men from Gaeltacht (Irish speaking) areas who spoke very limited English. In addition to the alcohol, music, cards and games whiled away the hours for Irish men with no "home" to go to, kept them in touch with their culture and protected them from homesickness, loneliness and isolation.

\section{A drinking subculture}

While the pub had an economic function for Irish men, it also played a significant role in challenging the status hierarchies which existed on building sites. Alcohol has long been regarded as a social leveller and drinking places provide for communication between people of different ranks and status (SIRC, 1998). Drinking establishments in different societies have norms and expectations of behaviour irrespective of social rank (Traeen and Rossow 1994). The egalitarian atmosphere of the "Irish" pub and the impact of alcohol were in contrast to hierarchies on a building site (Cowley, 2001, MacAmhlaigh, 1964). Irish pubs in different parts of the world are known for an oral culture of "slagging", a supposedly egalitarian levelling process aimed at challenging pretentiousness and retaining control (Share, 2003). The influence of alcohol and the 
flattened social structure of the pub allowed subbies (subcontractors) or gangers (foremen) to be teased, taken down a peg or at least spoken to without deference and with impunity. Conversely, prowess at conversation, cards or darts, a good singing voice or the ability to play an instrument afforded men with little status as labourers, a measure of prestige and self-esteem.

Drinking norms in most cultures include the reciprocal giving of alcohol (Heath, 2000) and are a central part of constructing and maintaining social, political and economic networks (SIRC, 1998). Reciprocity is inherent in the rules governing drinking and invariably includes rituals such as round-buying (Heath, 2000).

Walter, a former labourer describes the expectations of the building trade in the 1960s and 1970s.

"On building jobs, sure you had to row in with them and go along with them whether you liked it [drinking ]or not. It used to be about 10 or 12 pints a night. And maybe two whiskey chasers........"

While it was deemed unmanly and miserly for an Irish man not to buy a round, it was equally frowned upon and even insulting not to accept the drink bought by another (MacAmhlaigh, 1964, Cowley, 2001). In the informal economy of "the lump" men could ill afford not to buy a round when their work largely relied on social networks. In addition the social credit accrued when in work offset the leaner times when no work was available. Although the pattern of buying rounds first appears to be egalitarian, it is burdensome both economically and socially and the system of rounds meant that Irish men drank more as a group and for longer than they would have done as individuals. Cowley (2001) argues that subcontractors and publicans who offered advances on 
wages, delayed cashing cheques and encouraged a credit through a "slate", contributed to the heavy and prolonged drinking of Irish men in the construction industry.

\section{Drinking and masculinity}

The ability to drink heavily was closely related to perceptions of masculinity. Alcohol and the pub are important in the construction and the maintenance of masculinity in many cultures, not least among the Irish in Britain. There are many drink related rituals associated with achieving the status of manhood (Heath, 2000, Connell, 1987) and concerns about the association of alcohol and masculinity pervade contemporary literature (Harnett et al 2000). Rites of passage around alcohol exist in most cultures and the first alcoholic drink in a pub continues to be a "coming of age" and acceptance into male company in Ireland (Share, 2003)

Peter, a worker in an Irish community organisation identifies the role of alcohol in transition from adolescence to adulthood and highlights how men in the building industry remain part of a drinking subculture

For very young men it is still a rite of passage the whole thing about getting into drink and proving yourself........proving yourself as a true Irish man. But most men grow out of that [culture of heavy drinking], but some men remain in, who mix with that kind of crowd still continue particularly... historically on the building sites and that, you socialise by going out and drinking, but very heavy drinking. 
Several authors identify the link between conceptions of masculinity and ability to consume alcohol without exhibiting the impairments of intoxication (Heath, 2000, Westermeyer, 1985, Mandelbaum, 1965). Peace's (1992) study of fishermen in Ireland highlighted the requirement for them to "hold their liquor" and remain in control even having imbibed heavily. This is echoed in a number of historical, biographical and fictional accounts of Irish men in the UK construction trade (Cowley, 2001, MacAmhlaigh, 1964, 1985, Keane, 1993). However, the same accounts also emphasise the significance of physical strength and capacity for hard work as aspects of masculine identity. They describe how men with nicknames like Mule Kennedy, Bull Gallagher, Big Mick or Elephant John and others "horsed it out", digging trenches, tunnelling, pulling cable or laying concrete. Masculinity for Irish men was constructed on the basis of physical (animal) strength and the ability to consume large volumes of alcohol without staggering, being sick or out of control. It is therefore significant that when men were unable to work because of redundancy or ill-health, their whole image of themselves as men came under threat.

\section{Alcohol as self medication}

The nature of work, unsafe working conditions and lifestyle have taken a toll on the health of Irish men as degenerative disorders and industrial injuries contribute to excess economic inactivity in middle age (Aspinall, 2001). Physical illness expedites exit from the labour market and psychological ill-health and alcohol misuse often follow. The pub helps maintain continuity with the past and affords opportunities for odd jobs or occasional work when health allows (Tilki, 2003). Alcohol may be used to cope with physical pain or depression, to bolster self-esteem and deal with the emasculating effects of physical incapacity, economic inactivity or both. There is increasing awareness of the use of alcohol as a form of medication by Irish people. Tilki (2003) 
identified a stoic attitude to pain among Irish men and a particular reluctance to take medication, preferring to rely on the distraction, analgesic or amnesic effects of a few drinks. The following excerpt from a man in chronic pain reflects the narratives of several former construction workers, redundant or long term sick at end of the 1990s (Tilki, 2003). It also shows how alcohol and the company of the pub dulled the pain initially but in time led to dependence.

Int. M6. I just suffer on and going to the pub and a few jars and forgetting all about them [ pains and aches], until the next day anyway. It [alcohol] was a way of blocking out pain. It takes the edge off the pain. There's an element of pleasure in it to begin with but then the addiction, the whole lifestyle becomes associated with it.

There is a complex relationship between the construction industry, a subculture of drinking and the use of alcohol to cope with redundancy or ill-health and this may not be substantially different in any working class culture. However Tilki (2003) uncovered an additional Irish dimension, the impact of which should not be underestimated.

There is now widespread evidence that young people fleeing institutional and family abuses in Ireland from the 1950's until the 1970's came to Britain. They invariably had little formal education and were consequently forced to find work in unskilled occupations. Although not confined to labouring in the building trade, Tilki (2003) encountered a number of men (and women) who attributed their alcohol dependence and related mental and physical illness to earlier childhood factors. 
The following man, a heavy drinker with both physical and mental health problems described how he used alcohol to deal with flash-backs which he still suffered almost fifty years after having suffered physical, psychological and sexual abuse in an industrial school in Dublin.

Int. M7. I'm not saying it [the memory of abuse] hits me every day. It doesn't, but it does now and again, I can't sleep, it starts, this coming back into the mind.

Another man cited below was in recovery from mental illness originating in childhood sexual abuse by a family member. His mental ill-health was compounded by the use of alcohol and in turn impacted on the treatment offered (or not) by medical practitioners.

Int. M9 If you take away the Irishness and leave the drink - anybody who drinks the extent that I drank, there must be something wrong with them. I drank and I kind of couldn't handle it. I never drank continuously. Every now again I could go loopy, stressed out, and I used alcohol and occasionally street drugs. So yes I was suicidal. To be honest there wasn't a day went by when I wasn't suicidal. But could I get help? I was sitting in the waiting room reciting nursery rhymes and poems and talking rubbish and the general public could tell I was mad. But nobody was prepared to work with me or help me. "You are a drunk". The result to that is I ended up being arrested.

While this man believed his illness originated in child sexual abuse, the excerpt reflects the experience of other Irish people with mental health problems (Tilki, 2003). The use of alcohol to deal with the symptoms of mental illness resulted in a cycle of despair when his failure to access help increased his consumption and eventually led to a suicide attempt. 


\section{Alcohol, the pub and the younger Irish man.}

Although alcohol and the pub have been and still are entwined in a complex economic and social relationship for middle aged to older Irish men, there is a need to explore role of alcohol and the pub for those not employed in construction or manual occupations. Since the 1980s migrants from Ireland have been predominantly well educated and professionally qualified so the pub is therefore less significant economically. Mc Cambridge et al (2004) demonstrate heavy and frequent alcohol consumption among younger people, particularly young men which suggests that although the economic picture has changed there is still continuity. It is likely that young Irish people frequent wine bars and themed bars rather than more traditional pubs. It is also probable that the alcohol they chose is more varied and includes wine, designer beers and spirits rather than Guinness and all are more accessible because of higher disposable income.

Alcohol plays a central role in major life cycle events and is associated with celebration and festivity. It is also used to mark everyday transitions such as the distinction between work and leisure. Oldenburg (1999) proposes the pub as a "third place", a space which marks the transition from work to home and is probably as relevant for Irish men today as it has been in the past. The environment, the type of alcohol and the nature of drinking partners may have changed but a binge culture persists. There is much concern in the UK about increasing alcohol use and binge drinking among the young population, particularly on Friday and Saturday nights. The following young interviewee described a culture of drinking among young people working in the City, which initially helped him cope with the stresses of work, but had created other problems. He had since cut down and now considered himself a moderate social drinker. 
Int. M20. It seems so hard to unwind without taking work home with you, that the easiest thing is to go to the pub and try and drink it away rather than to actually deal with it.

However although work colleagues were mainly English people, the friendships he developed were with the few Irish people who (then) worked in the City. He believed there was an added and particularly Irish dimension to the work-related drinking culture.

Int. M20. a lot of people drink, who work in the City in stressful jobs, but I'd say we [Irish] were less measured. We would always have been drinking more, to a much greater excess.

The account is not dissimilar to the findings of McCambridge et al (2004) in that the informant is highly educated and earning a good salary. Although not having the same economic function as in the construction industry, it is possible that the pub (or wine bar) facilitates social networks which are important in the business and financial world occupied by young Irish people today. It is probable that the pub or wine bar provides the opportunity to meet Irish and other people of similar backgrounds and interests that one would not meet in more traditional Irish settings. While not having to tolerate the extent of anti- Irish racism experienced by their predecessors, more recently arrived Irish people still perceive a sense of "otherness" and not quite belonging (Tilki, 2003).

\section{Alcohol - a culturally sanctioned coping strategy?}

There is evidence of a relationship between the experience of being Irish and the use of alcohol to cope with physical or psychological pain and social alienation (Tilki, 2003). Higher levels of 
alcohol and dangerous patterns of consumption are not confined to Irish people but are also evident in other deprived groups (Erens et al 2001, Wardle et al 1999). However although structural factors engender psychosocial stress, culture appears to determine the acceptability of certain health behaviours as coping strategies. Using alcohol as a form of release is likely to be a culturally acceptable coping strategy for Irish people and plays a significant role in coping with stress and illness and providing pleasure for Irish men and women (Tilki, 2003). There is no indication that Irish people lack knowledge about the link between alcohol and ill-health but consumption is influenced by wider social factors and is closely linked with the experience of being Irish in London (Tilki, 2003). Lupton (1995) argues that people choose to indulge in health harming behaviour because it is pleasurable and for some because life is mostly outside their control. Using alcohol not only affords pleasure in a difficult life, but affords a sense of control in a world where one has little influence.

While alcohol may afford a sense of control for disadvantaged and deprived people it is less likely to be so for more privileged groups. It is more likely to relate to the growing use of what Pellegrino (1976) and Warburton (1978) refer to as "chemical comforters" and part of a culture which involves an absence of anxiety, anger or stress. Despite being aware of the negative consequences of excessive consumption, participants in the Mc Cambridge et al (2004) study saw few reasons to change their behaviour. This probably reflects peer group expectations, status, hedonism and youth and suggests failure to take responsibility for their health. However Chamberlain and O Neill (1998) and Lupton (1995) argue that people from higher socio-economic groups feel in control and believe they are responsible for their own destiny. In engaging in health harming behaviour it is possible they believe that other aspects of their lives will protect them and they will be able to alter if and when they decide to do so (Chamberlain and O Neill,1998); Lupton,1995). However this denies the risk of 
dependency or the unanticipated adverse consequences which can result from just one single heavy drinking occasion.

\section{Disentangling the relationship between alcohol and Irishness}

Almost three decades ago, Cochrane (1977) offered three hypotheses to explain the high incidence of mental illness among the Irish in Britain. His suggestion that patterns of high consumption in Ireland were reflected in the drinking behaviours of Irish migrants in the UK evoked criticism and much offence at the time. Almost thirty years later Mc Cambridge et al (2004) suggest that hazardous drinking patterns are normative among young people in both London and Dublin. Although cautious about the generalisability of the sample, they question the relationship between being Irish in England and the continuation of some Irish drinking practices on moving to London. Concerns exist about alcohol consumption among youth in general, but the Mc Cambridge study suggests that the Irish in London differ in one significant respect. While the frequency of consumption was similar to the UK population in general, levels of consumption were higher reflecting those reported in Ireland by the Strategic Task Force (2002). Mc Cambridge et al (2004) also noted a high rate of parental history of alcohol problems in their samples in both London and Dublin. Greenslade (1995) highlights tolerant attitudes to drink and drink related problem in Ireland which co-exist with high levels of abstinence. While there are clearly many variables at play, questions must be asked about attitudes to alcohol in Ireland which might be continue to relevant to Irish people in the UK.

\section{Ireland -an ambivalent alcohol culture}

Share (2003) argues that Ireland is unusual in that a culture of teetotalism coexists with one of high drink consumption. Although there has always been and continues to be a high level of 
abstinence in Ireland, there is evidence of increasing alcohol consumption with rates rising from second lowest in Europe 1989 to second highest in 2002 (Strategic Task Force on Alcohol Interim Report 2002). The number of abstainers has declined and is still two to three times higher than other European states, but it does not account for the increased per capita consumption of alcohol (Simpura and Karlssen, 2001). The high levels of abstention suggest particularly high consumption and research shows that people in the Irish Republic are more likely to engage in binge drinking than their European counterparts (Slán, 2003). There are gender and age differences but the problem is greater for younger people and especially for men who experience more adverse and harmful consequences of drinking.

\section{(http://www.healthpromotion.ie/uploaded docs/Irish Drinking Culture.PDF)}

Cassidy (1998) describes attitudes towards alcohol consumption and alcoholism in Ireland as ambivalent since alcohol is condemned while at the same time having a key role in society. Ireland is a culture of both abstinence and excess (Ferriter, 1999) and drink is seen as both a pleasure and a problem (Inglis, 2002). The dichotomous attitudes of tolerance and abstention contribute to ambivalence and present an obstacle to acknowledging and dealing with alcohol problems (Greenslade, 1995). The focus on abstention means that young people are not taught to drink safely as they are in more permissive alcohol cultures in Southern Europe. In the in the absence of suitable role models those who do not want to follow the route of abstinence learn to only to drink excessively. The problem is currently magnified by high levels of disposable income and the aggressive marketing of alcohol products. While binge drinking among young people is a concern in many countries, it is possible that ambivalent attitudes in Ireland mean it becomes less a rite of passage and more a way of life especially for men. Greenslade (1995) describes the problem of alcoholism as "a good man's fault", where the heavy drinker is treated 
with forbearance rather than disapproval. He suggests that in the Irish culture of masculinity the heavy drinker is not lionised but is neither seen as particularly aberrant. The absence of much research in this area is a problem, but it is possible that ambivalent attitudes from Ireland persist among Irish people in the UK and perpetuate alcohol related problems among younger Irish men. Some research locates this tolerance in Catholicism, a key aspect of Irish identity at home and abroad. It has been shown that even many generations following migration, Irish culture cannot be divorced from the influence of Catholicism which has affected a greater tolerance towards alcohol misuse among Catholic families when compared with Protestant families (Walls, 2005).

Given the colonial relationship between Ireland and Britain and continued tensions over Northern Ireland it is possible that for young Irish people, drinking is a political act of defiance. The scope of the article does not allow more than a cursory mention of the body of literature on aboriginal drinking (Room, 1984; OConnor, 1984; Moore, 1992). Although not without its critics, this body of work is worthy of further exploration given Ireland's colonial and oppressive past. In the past the pub provided a safe haven but with a more confident community today, drinking could be a defiant gesture rather than a retreat. Communal drinking may be a form of everyday resistance which affords a sense of power or equality. It may facilitate a separate and Irish identity through sharing and resistance against an authoritative and controlling "nanny" state.

\section{Alcohol and the pub in the wider context of being Irish in Britain.}

While it is crucial to tackle the destructive aspects of alcohol consumption it is also important that we do not lose sight of the beneficial effects (Moore, 1992) and particularly the merits of the pub. Aside from its economic function in relation to the construction industry, the pub still provides a meeting place for those living in poor accommodation or more commonly now those living in disparate parts of London. The "Irish" pub offers a sense of community for those who are 
reluctant to access other opportunities for social contact such as the Church or the local Irish centre. There is evidence that younger Irish people are uncomfortable identifying with a traditional Irish scene in a 1950s time warp (Tilki, 2003). The pub, whether authentically Irish or themed is more likely to afford access to contemporary Irish music and culture and an environment where it is safe to be Irish. Health related behaviours such as alcohol use and smoking reflect the wider patterning of social life (Tilki, 2003). Given the persistent stress experienced by sections of the Irish community, the potential for culture shock and homesickness and continued perceptions of "otherness", the camaraderie of the pub and the pleasure, release and self indulgence associated with alcohol must not be underestimated. This understanding must inform therapeutic practice and health promotion strategies for Irish people experiencing or in danger of alcohol related problems.

Alcohol misuse among Irish people in Britain is clearly fraught with sensitivity for both policy makers and practitioners. However there is a significant problem now and a burgeoning one for the future if the issue is not tackled with urgency and sensitivity. Given the evidence of dangerous patterns of consumption, the unequivocal poor physical and mental health and high levels of suicide among Irish people in Britain urgent action is needed at national and local policy level. Statutory providers should explore opportunities for partnerships with Irish voluntary sector organisations in the areas where these exist. A number of examples of good practice exist in this sector but energy is needed to build the capacity to meet the demand. Initiatives to address diversity must include an Irish dimension if those working with Irish men are to be culturally competent and anti-discriminatory in their practice. The NHS Alcohol Strategy and is a timely opportunity to address the needs of Irish people and there is a strong business case and a moral one for doing so. 


\section{References}

Aspinall P. (2001) The health status, health services utilization and health related behaviours of adult Irish men in an Inner London Borough : The findings of a population-based Health and Lifestyle Survey. Tunbridge Wells. Centre for Health Services Studies. University of Kent.

Bracken P., Greenslade L., Griffin B., Smyth M. (1998) Mental health and ethnicity : An Irish dimension. British Journal of Psychiatry, 172, 103-105 .

Canning U., Kennell-Webb S., Marshall E., Wessely S., Peters T., (1999) Substance misuse in acute medical admissions. Quarterly Journal of Medicine 92, 319-326

Cassidy T (1998) 'Just two will do' in M. Peillon \& E. Slater (eds) Encounters with modern Ireland: A sociological chronicle 1995-1996. Dublin: Institute of Public Administration.

Chamberlain K., O Neill D. (1998) Understanding social class differences in health: A qualitative analysis of smokers' health beliefs. Psychology and Health, 13, 1105-1119.

Cochrane R. (1977) Mental illness in immigrants to England and Wales: An analysis of mental hospital admissions, Social Psychiatry, 24, 2-11

Cochrane R., Bal S. (1989) Mental hospital admission rates of immigrants to England. A comparison of 1971 and 1981. Social Psychiatry and Psychiatric Epidemiology, 24, 2-11 
Commander M., Odell S., Sashidaran S., Surtees P. (1999a) Psychiatric morbidity in people born in Ireland. Social Psychiatry and Psychiatric Epidemiology, 34, (11), 565-9

Commander M., Odell S., Sashidaran S., Surtees P. (1999b) Pathways to care for alcohol use disorders. Journal of Public Health Medicine, 21,(1), 65-69

Connell R (1987) Gender and power: Society, the person and sexual politics. Sydney: Allen and Unwin.

Cowley U (2001) The men who built Britain : A history of the Irish navvy. Dublin. Wolfhound Press.

Dean G., Downing H., Shelley E., (1981) First admissions to psychiatric hospitals in south-east England in 1976 among immigrants from Ireland. British Medical Journal 282, 1831-1833

Farren C, Martin S (2004) Alcohol and Suicide : Interim Findings. Dublin. Dual Diagnosis Treatment Centre, St Patrick's Hospital.

Ferriter D (1999) A nation of extremes: The Pioneers in twentieth-century Ireland. Dublin: Irish Academic Press.

Foster J. (2003) The Irish alcohol misuser in England. : Ill served by research and policy? Some suggestions for future research opportunities. Drugs :Education, Prevention and Policy, 10, 1, 57-63 
Foster T. (2001) Dying for a drink? British Medical Journal, 323, 817-818

Greenslade L. (1997). The blackbird calls in grief: Colonialism health and identity among Irish immigrants in Britain. In J. Mac Laughlin (ed) Location and dislocation in contemporary Irish society : Emigration and Irish identities._Cork. Cork University Press.

Greenlslade L. (1995) A good man's fault: Alcohol and Irish people at home and abroad. Alcohol and Alcoholism, 30, 4, $407-417$

Harnett R, Thom B et al (2000) Alcohol in transition : towards a model of young mens' drinking. Journal of Youth Studies, 3, 1, 33-47

Harrison L., Carr Hill R. (1992) Alcohol and disadvantage amongst the Irish in England. London. Federation of Irish Societies.

Harrison L., Sutton M., Gardiner E., (1997) Ethnic differences in substance use and alcohol related mortality among first generation migrants to England and Wales. Substance Use and Misuse 32, 849 $-876$

Harrison L., Carr-Hill R, Sutton M (1993) Consumption and harm :Drinking patterns of the Irish, the English and the Irish in England. Alcohol and Alcoholism, 28, 6, 715-723

Heath D. (2000) Drinking occasions : Comparative perspectives on alcohol and culture. Philadelphia. Brunner Mazel. 
Hickman M., Walter B. (1997) Discrimination and the Irish community in Britain. London. Commission for Racial Equality.

Hillyard P. (1993) Suspect community : Peoples' experience of the Prevention of Terrorism Act in London. London. Pluto.

Inglis T (2002) 'Pleasure pursuits' in M. Corcoran \& M. Peillon (eds) Ireland unbound: A turn of the century chronicle. Dublin: Institute of Public Administration.

Keane J.B. (1993) The contractors : A novel . Cork. Mercier Press.

Kowarzik U. (2001) Irish community services: Meeting continuing need. London. Action Group for Irish Youth / Federation of Irish Societies.

Kowarzik U. (2000) Irish community services: Responding to need. London. Action Group for Irish Youth / Federation of Irish Societies.

Leavey G. (1999) Suicide and Irish migrants to Britain: Identity and integration. International Review of Psychiatry, 11, 168-172.

Luce A., Heather N., M Carthy S. (1999) National census of UK alcohol treatment agencies : Characteristics of clients, treatment and treatment providers. Journal of Substance Use 2, 112 120 
Lupton D. (1995) The imperative of health: Public health and the regulated body. London. Sage.

Macken W. (1949) I am alone. London. Pan Books Macmillan.

Mandelbaum, D.G. (1965). Alcohol and culture. Current Anthropology, 6, 3, 281-293.

Mc Cambridge J., Conlon P., Keaney F., Wanigaratne S., Strang J., (2004). Patterns of alcohol consumption among the Irish in London : A preliminary comparison of pub drinkers in London and Dublin . Addiction Research and Theory, 12, 4, 373-384

Mac Amhlaigh D. (1964) An Irish navvy : The diary of an exile navvy. London. Routledge Kegan Paul.

Mac Amhlaigh D. (1985) Schnitzer O Shea._Dingle. Brandon Press.

Moore D. (1992) Beyond the bottle: Introducing anthropological debate to research into Aboriginal alcohol use. Australian Journal of Social Issues, 27, 3, 173-193.

NIMHE (2003) Inside outside : Improving mental health services for Black and minority ethnic communities in England. NIMHE/Department of Health.

OConnor R (1984) Alcohol and contingent drunkenness in central Australia. Australian Journal of Social Issues, 19, 3, 173-183 
Oldenburg R (1999) The great good place: Cafes, coffee shops, bookstores, bars, hair salons, and other hangouts at the heart of a community. New York: Marlowe.

Peace A (1992) No fishing without drinking : the construction of social identity in rural Ireland. In D. Gefou- Madianou (ed) Alcohol, Gender and Culture. London. Routledge

Pellegrino E. (1976) Prescribing and drug ingestion :symbols ans substances. Drug Intelligence Clinical Pharmacology, 10, 624-630

Room R (1984) How good an excuse is drunkenness (Unpublished manuscript cited in B. Critchlow . The powers of John Barleycorn : beliefs about the effects of alcohol on social behaviour. American Psychologist, 41, 751-764

Share P (2003) A genuine third place ? Towards an understanding of the pub in contemporary Irish society. Work in progress paper. Sociological Association of Ireland Annual Conference, Ballyconnell, 26 April 2003.

SIRC (1998) Social and cultural aspects of drinking. A report to the Amsterdam Group. Oxford. Social Issues Research Centre.

Simpura J., Karlsson T (2001) Trends in drinking patterns in 15 European countires 1950-2000. A collection of county reports. Helsinki, Stakes.

Slán 2003. The national health and lifestyles surveys. Centre for Health Promotion Studies. NUI, Galway and Department of Health and Children. 
Strategic Task Force on Alcohol (2002) Interim Report. Dublin. Department of Health and Children.

Træen, B. and Rossow, I (1994). Social characteristics of urban café guests in Norway. Addiction, 89, 999-1006.

Walls P. (1996) Researching Irish mental health : Issues and evidence : A study of mental health of the Irish community in Haringey. London. Muintearas.

Walls P (2005) The health of Irish descended Catholics in Glasgow : A qualitative study of the links between health risk and religious and ethnic identities. Unpublished $\mathrm{PhD}$ thesis. University of Glasgow.

Warburton D. (1978) Poisoned people :internal pollution. Journal of Biosocial Science, 10, 30919

Wardle J., Farrell M., Hillsdon M. et al (1999) Smoking, drinking, physical activity and screening uptake and health inequalities. In Gordon D., Shaw M., Dorling D., Davey Smith G.(eds) Inequalities in Health: The evidence presented to the Independent Inquiry into Inequalities in Health Chaired by Sir Donald Acheson. London. The Policy Press.

Westermeyer, J.J. (1985). Hmong drinking practices in the United States: The influence of migration. In L.A. Bennett and G.M. Ames (eds.), The American Experience with Alcohol: Contrasting Cultural Perspectives. New York: Plenum Press. 